\title{
ON THE EU GREEN DEAL AND BUILDING BRANCH
}

\author{
Yatchko Ivanov*, Ana Yanakieva and Robert Kazandjiev \\ Institute of Mechanics, \\ Bulgarian Academy of Sciences, \\ Acad. G. Bonchev St., Bl. 4, 1113 Sofia, Bulgaria, \\ e-mails:yadir_1@abv.bg; aniyanakieva@imbm.bas.bg; \\ e-mail: robert@imbm.bg
}

\begin{abstract}
The EU Green Deal was made to enhance the participation of states facing problems of climate change. The task is to realize policies and actions enabling Europe to become the first climate-neutral continent by 2050 . Since building branch is one of the greatest consumers of resources and emitter of carbon dioxide, as well as one of the biggest employers in Europe, the branch should actively participate in the Green Deal. Its participation requires transformation from a carbon emitter to a carbon absorber; transition to sustainable use of the natural resources; contribution to the decrease of energy insufficiency; operation as part of circular economy and under COVID-19 pandemic; employment of digital technologies and active participation in the establishment of an economy that would stimulate competitive position, improve the quality of life and labor of the European residents and build a stronger and ecology-friendly society. Following the scope of the Green Deal and the New Bauhaus Initiative, the present study is an attempt to analyze the capability of the building branch to solve the problems facing Europe's transformation into a green continent.

Keywords: Green Deal, New Bauhaus Initiative, COVID-19 pandemic, building branch, sustainable development, information technologies, natural resources.
\end{abstract}

\section{INTRODUCTION}

The intensive development of industry during the past century - a century of discoveries, composite materials, and IT technologies, posed at the turn of the century serious issues of climate change and protection of the natural environment, together with its positive impact on society. Frequent energy crises emerged during the last decades of the $20^{\text {th }}$ century, being a serious challenge

${ }^{*}$ Corresponding author.

DOI: 10.7546/EngSci.LVIII.21.03.05

Engineering Sciences, LVIII, 2021, No. 3 
to mankind. A new paradigm of sustainable development became actual, being an approach to the usage of natural resources, but without violation of the environmental balance. Sustainable development unites two basic pursuits of society: (i) economic development providing rise of the living comfort; (ii) protection and improvement of the natural environment (care for the future).

According to the World Commission on Environment and Development, "sustainability means meeting the actual needs of humanity, but without compromising the right of future generations to meet their needs" [1].

The outlined issues generate a new attitude to the environment and future of mankind concerning all areas of human activity. This complex situation is accompanied by the extremely rapid increase of the human population. According to recent estimates, the human population by 2050 will amount to 10.9 billion people. The rapid increase of the population and urbanization would require an adequate increase of resources needed for construction and human feeding. The outbreak of the COVID-19 pandemic posed additional problems.

We face a significant unfavorable climate change due to the emission of greenhouse gases.

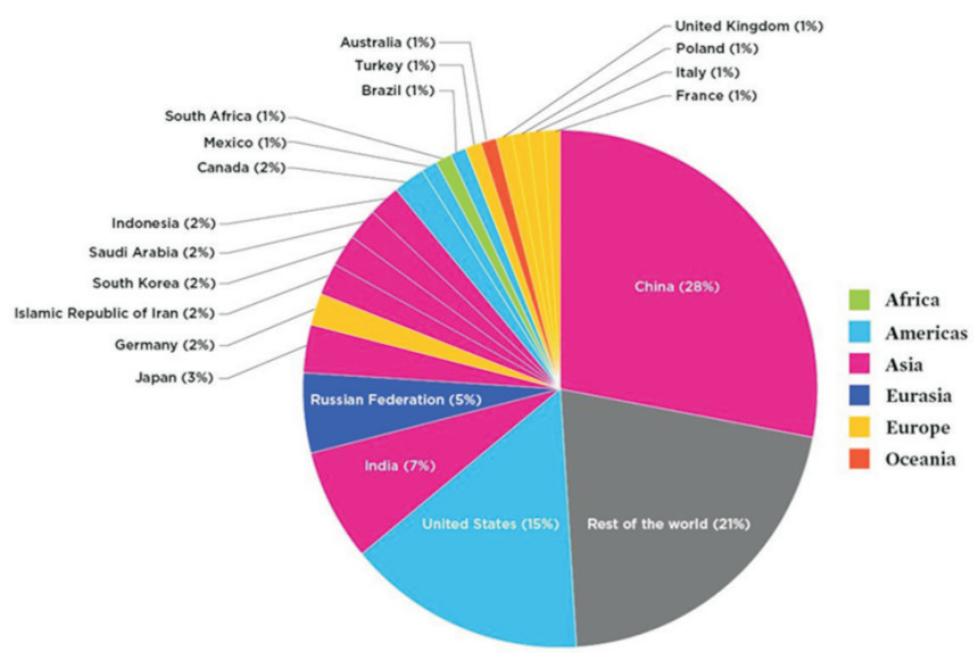

B 2020 Union of Concerned Scientists
Data Earth Systems Science Data 11, 1783-1838, 2019

Fig. 1. States with significant emission of $\mathrm{CO}_{2},[2]$

Figure 1 shows continents and states emitting significant amounts of $\mathrm{CO}_{2}$. It is seen that China is with the largest share (28\%), followed by the USA (15\%), India (7\%), Russian Federation (5\%), Japan (3\%), while 6 states are 
with $2 \%$ share and 7 states - with $1 \%$ share of $\mathrm{CO}_{2}$. The rest of the world (including Bulgaria!) emits a total amount of $21 \%$ of $\mathrm{CO}_{2}$, with less than $1 \%$ of $\mathrm{CO}_{2}$ release per state.

Madam Ursula von der Leyen delivered a speech on 16.08.2020 in Brussels where she analyzed the state of the Union under the COVID-19 pandemic, noting that it is a global crisis and the need for learning global lessons [3]. Since member states tackled the crisis in a non-organized manner, she appealed for the creation of a European Health Union guaranteeing that the new program "EU for Health" will resist modern-day trials. She also announced the creation of a European Agency for Modern Biomedical Research and Measures strengthening the European Drug Agency and the European Center for Prevention and Control of Diseases. Another accent was on the green policy of the Union, and she appealed for larger cuts of carbon emissions ( $55 \%$ decrease by 2030 instead of the $40 \%$ as planned), which would guarantee a zero $\mathrm{CO}_{2}$ emission by 2050. Madam von der Leyen noted therein that our buildings generate $40 \%$ of the carbon emissions, and this should stop. Building branch should dissipate fewer resources, the latter becoming cheaper and more sustainable. She also expressed her confidence in the transformation of the building branch (from a $\mathrm{CO}_{2}$ source to a $\mathrm{CO}_{2}$ absorber), using organic building materials, wood, intelligent technologies, and IT. She announced the already discussed idea for the creation of a European Bauhaus Space for joint design, where architects, artists, students, engineers, and designers could work on the formation of a Next Generation EU for an independent design of a world we want to live in. This will be a world operated by the economy, decreasing harmful emissions, stimulating competitiveness, decreasing energy "poverty", and creating satisfying jobs with improved labor and life quality - a world employing IT to build a more sustainable and ecology-friendly society [3]. These issues are in accordance with the philosophy of the Davos Economic Forum held earlier, where the present pandemic became a cause for overthinking World's future. A new "Net Zero" initiative was virtually launched in Davos aiming at the introduction of more social and ecology-responsible models bound to replace modern capitalism. The founder and executive chairman of the Davos forum, Dr. Klaus Schwab, pointed out in this respect that all aspects of our society and economy should reform following a course "from education to social contracts and labor conditions" [4]. Hence, we need "New investments in people and environment" [5]. Digitalization and the resulting transformation should be the key instruments in achieving that goal. The "Net Zero" initiative is to be developed, together with the realization of the "Sustainable development" paradigm, sustainable construction, Net Generation EU, and 
the announced Green Deal. These require a fundamental change of the policy of EU and EU member states. Hence, new issues face the building branch.

\section{GOALS OF THE GREEN DEAL}

On 11.12.2019 [3] Ursula von der Leyen declared the Green Deal or the green package as a program of the new governing body of the EU, thus announcing the pursuit of a policy guaranteeing better health to modern and future generations providing: cleaner energy, renovation, modernization and energy efficiency of residential and public buildings; cleaner and ecological public transport, cars, air, water, soil, and healthier food, using less pesticides and artificial fertilizers. The Green Deal will be realized using a set of policies and documents whose following will enable Europe to become the first climate-neutral continent by 2050 .

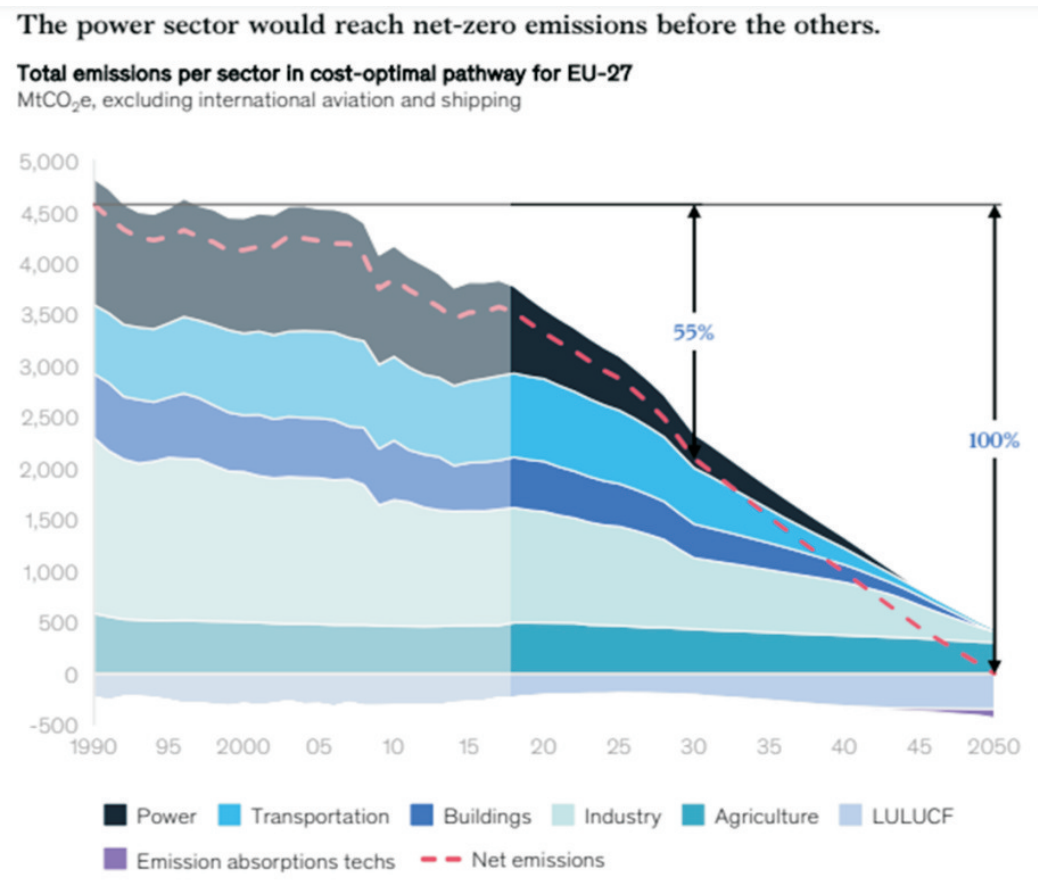

Fig. 2. Total amount of $\mathrm{CO}_{2}$ emissions, $[6]$

The total amount of $\mathrm{CO}_{2}$ emissions of the member states by 1990 was 5000 Mt according to [6], Fig. 2. The industrial share was the largest one (almost $2000 \mathrm{Mt}$ ) while that of building was $1000 \mathrm{Mt}$. Decreasing the emissions to 
$55 \%$ by 2050 , the share of the 27 member states will be less than $2000 \mathrm{Mt}$, while that of the construction branch will be about $500 \mathrm{Mt}$.

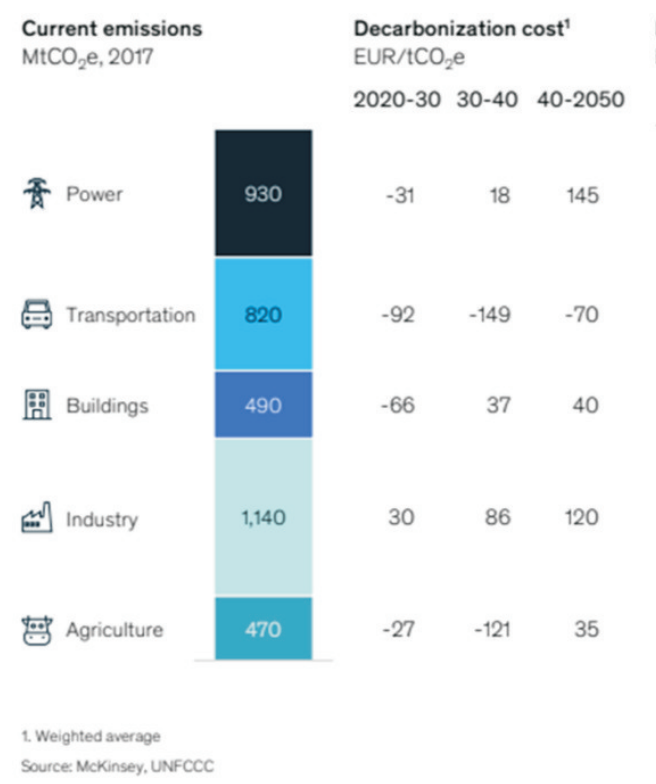

(a)
Emissions evolution $\mathrm{MtCO}_{2} \mathrm{e}$

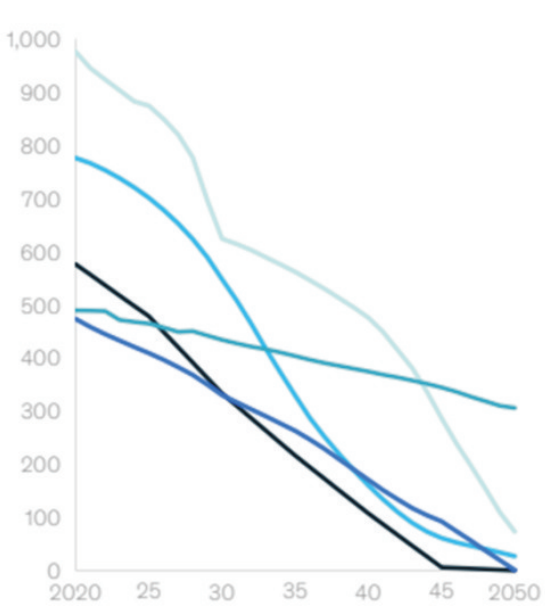

Fig. 3. Rates of emission drop till 2050

Figure 3 shows the decrease of emission rate till 2050, whose achievement will guarantee Europe's climate neutrality [6]. Under the adopted program, the general introduction of renewable energy sources is expected to result in the fastest achievement of zero emission by industry. Checks and corrections are planned and new laws will be introduced concerning circular economy, climate, energy generation, the energy consumption of buildings, biological variety, agriculture, innovations. Europe's total neutrality to climate changes will be guaranteed by the pursuit of new laws for climate and energetics, which are currently under preparation. They will attribute to the design of climate-neutral energetics. All EU energy documents especially stress the intelligent sectorial integration of renewable energy sources, electro- and heat generation, and decarbonization of natural gas. The action plan of the EU circular economy encourages the manufacture of sustainable (green) products for multiple use. The following important issues were announced in 2020 and the first half of 2021 under the policies of the Green Deal:

- 13.08.2020, Engagement of the European residents in the design of the agenda of the missions of the EU Framework program for scientific re- 
search "Horizon Europe" (2021-2027) [7]. Five areas of the possible missions adopted by the Parliament were discussed: cancer; adaptation to climate changes including social transformations; healthy oceans, sea sides, and internal water basins; climate-neutral and intelligent towns; healthy soil and food. Public discussions and consultations were held in Latvia, Greece, Poland, and France during three of the missions [8].

- 06.08.2020, Organization and realization of events for handling the COVID19 pandemic, including the foundation of a European Health Union with a task to guarantee that the new program "EU for Health" will stand the test of time; the foundation of European Agency for Modern Biomedical Research and Development, enhancement of the European Drug Agency and a European Center for Prevention and Control of Diseases, as well as enhancement of the implementation of the EU Green Deal policies [9].

- An online seminar with the participation of Madam Ursula von der Leyen and the Prime Minister of Portugal was held in May [10], where the development of the "New Bauhaus" initiative was discussed. Its good start was noted, while 440 thousand positions, recommendations, and proposals on the matter were received (25 thousand of them were from construction companies). Note that a significant tribute of the initiative to climateneutral Europe is expected. Awards for significant tributes in the field were established.

- April 2021, the EU invited member states of the European Alliance for clean hydrogen to present projects on renewable low-carbon technologies and solutions. Thus, a package of means for the achievement of the goals of the Hydrogen Strategy guaranteeing climate-neutral Europe can be designed [11]. It is expected that clean hydrogen will be a key factor in the decarbonization of many sectors of the economy and the establishment of sustainable competitiveness of the EU industry. The task is to install by 2024 electrolysis equipment for hydrogen from renewable sources with 6 GW power, and by 2030 - equipment with $40 \mathrm{GW}$ power. Thus, growth and employment will be supported. The expected applications of hydrogen technology are in mobility, industry, energetics, and heating, contributing to the decrease of greenhouse gas emissions.

- In response to the COVID-19 pandemic Madam von der Leyen declared a Recovery and Stability Plan for Europe in October 2020, and the members of the European Parliament agreed to add a recovery fund to the adopted EU budget 2021-2024 [12]. It will guarantee the fulfillment of the program "Next generation EU". The majority of member states prepared and presented their plans for recovery and sustainability guaranteeing reform 
implementation and subsequent funding by 2026 .

- As of now however some states are late with the preparation of their plans, and Bulgaria is one of them. It is expected that those plans will be coordinated and approved by the EC in the coming months, payments starting in the summer of 2021. Thus, the reforms and plans for public investments would guarantee the realization of the Green Deal.

- Bauhaus's idea announced in 2020 was further developed at the online "New European Bauhaus" conference held in April [11,13]. Madam von der Leyen defined its goal, namely: "We want to make the European Green Deal notable via the "New European Bauhaus". This is of essential importance for the achievement of our common goal - a transformation of Europe into the first climate-neutral continent by 2050". She was confident that architects, artists, designers, engineers, students, and scientists will participate in this new European initiative. More than 440000 individuals supported the idea via comments and opinions. Hence, we find the "New European Bauhaus" to be a project of hope and change.

- Gradual replacement of coal as an energy source with gas and pure hydrogen is forthcoming. In this respect, the EU undertook measures to compensate the regions of the member states most affected by the removal of energy generators on coal [14].

We expect that the Green Deal will be an investment catalyst helping to the removal of energy "poverty" and the solution of the EU demographic problems. It will also have a positive geopolitical impact [15]. According to some views, the solution of the problems of climate change would decrease the threat of large migration supporting the national security of the member-states.

\section{BUILDING BRANCH TASKS}

The branch is the largest employer in Europe [16-17]. It provides $9.9 \%$ of the Gross Domestic Product (GDP) and $54.9 \%$ of the Gross Fiscal Capital (GFC) employing 14.9 million workers (6.4\% of Europe's total employment) and almost $29.3 \%$ of the industrial employment. It also provides 18 million direct jobs, while 43.6 million workers directly or indirectly depend on the building branch. Moreover, there are 3.1 million operating companies where $95 \%$ are small and medium companies employing less than 20 employees, and $93 \%$ are small companies with less than 10 employees. They operate on the local market and within a strongly standardized environment. Statistics proves that 1 Euro spent in construction generates 3 Euro in the global economic activity. Hence, building branch is one of the important driving forces of EU 
economy, and it should play its important part in the execution of the Green Deal. At the same time, construction is one of the largest European consumers of resources.

Considering the entire living cycle of an EU building (extraction of raw materials, manufacture of construction products, construction, exploitation, control, and demolition) statistics shows that the construction branch accounts jointly for [18]:

- Half of the extracted raw materials;

- Half of the consumed energy;

- One-third of the consumed water;

- One-third of the generated waste.

A European resident generates about 5 tons of waste annually, where only a limited volume is recycled (only $39 \%$ of the generated 26 billion tons of waste have been recycled in 2004). A large part of the remaining waste is still kept in disposals or has been transferred to incinerators. In this respect, Bulgaria has generated 3 million tons of construction waste in 2004: concrete/steel reinforcement $-29 \%$; ceramics $-14 \%$; asphalt $-11 \%$; mixed waste $-9 \%$; wood, metal, paper (bound to recycling) $-4 \%$; hazardous waste $-1 \%$; soil and rock $35 \%$. All the waste is spread all over the territory, and an insignificant volume is stored in disposals.

Construction, being of essential importance for the living environment, economy, and the well-being of mankind is not an exception to modern tendencies. Moreover, Vitruvius defined architecture as a "design of comfort and sustainability" even in his first writings on construction "Ten books on architecture (DeArchitectura)".

In modern times, this is a guarantee of preciseness, stability, and beauty. Harmony may be added as an additional feature of construction providing unity between building and environment.

"The Europe 2020" program was our basic document till 2020, planning [19]:

- Drop of greenhouse gas emissions by over $20 \%$ as compared to 1990 ;

- Generation of $20 \%$ of energy from renewable sources;

- Increase of the energy efficiency by $20 \%$;

- Use of at least $70 \%$ of recycled materials.

These tasks related to climate changes were the basis of the program "Europe for efficient use of resources". There are still no complete data on their fulfillment, but it is obvious that branch did not achieve the planned usage of recycled materials as a whole. The starting point of construction analysis within the context of sustainable development and the "Europe 2020" strategy 
is the fact that it is still far from sustainable. For instance, the manufacture of the main construction materials consumes a significant amount of energy and resources, releasing large amounts of oxides and affecting the environment $\mathrm{CO}_{2}, \mathrm{NOx}$, and SOx.

The local use of recycled materials is regulated by the Act of Waste Management and the Regulation of the management of construction waste and the use of recycled materials, 2003 (Publ. State Gazette, No. 89, 13.11.2012 and amended 2017). According to the Regulation, the separate collection of waste from construction and demolition started 1.01.2014. Recycled materials in public construction sites should be used [20]:

- for new buildings $-2 \%$;

- for roads $-10 \%$;

- for highway rehabilitation - 3\%;

- for new construction and infrastructure reconstruction - 8\%;

- in back fillings - $12 \%$.

These quantities were mass percepts of the general amount of planned and used construction materials, and they were to be observed in stages till 2020, according to the Regulation terms. Yet, we were late in providing enough power for construction material recycling. One may find that the issue has been partially solved for now, especially in the recycling of waste from road pavement. Add also herein the Regulation (EU) No. 305/2011 of the European Parliament and the EU from 03.2011, specifying the harmonized conditions of market offerings of construction products. Regarding the canceled Directive 89/106/EEC of the EU, a new basic requirement for construction is added, i.e. a sustainable use of natural resources guaranteeing agreement with the requirements of the Green Deal.

Note the stronger requirements to construction introduced by the Green Deal, which considers a significant drop in carbon emissions [20], especially during the manufacture of cement and steel. Note also the respective approaches of cement manufacture [21-22]: design of new cement brands with facilitation of $\mathrm{CO}_{2}$, manufacture of calcium-silicate cement brands (experiments of Solidia Technologies), use of raw materials as additives during cement manufacture (sulfur-ferro-alumo-cement clinker) [23], as well as additives of industrial origin. The first experiments prove that the current approach is the correct one, but more developments and solutions of construction material science are expected. These activities should take place during the next few years, since Europe unified by the Green Deal, undertook new and decisive measures in providing carbon security and climate neutrality.

Engineering Sciences, LVIII, 2021, No. 3 
The building branch should significantly decrease the carbon emissions during construction and exploitation of buildings and facilities, turning from $\mathrm{CO}_{2}$ emitter to $\mathrm{CO}_{2}$ consumer. Thus, the branch will be prepared to react to the expected prognoses of the International Finance Corporation, World Bank Group [24] to decrease the climate risk and follow the new approaches. A significant rise in the prices of carbon emissions is expected in this respect.

An important task of the construction branch is also active participation in the treatment of problems of energy "poverty" by improving the energy characteristics of buildings and enhancing the control of whether they agree with the normative regulations. The announced "new wave of rehabilitation" is a serious challenge to the construction business. Its goal is to double the annual share of rehabilitation of buildings (at present amounting to $0.4-1,2 \%$ for member states), attract investments, increase durability with respect to climate changes and significantly decrease the energy "poverty" as well as the consumed energy (by 40\%). Thus, rehabilitation can provide support for small and medium construction companies and create local jobs. There is much to be done in the construction of Nearly Zero energy Buildings (NZEB) involving renewable energy sources. An NZEB is shown in Fig. 4 where the building is supplied from solar panels with power $30 \mathrm{GW}$ [25-26].

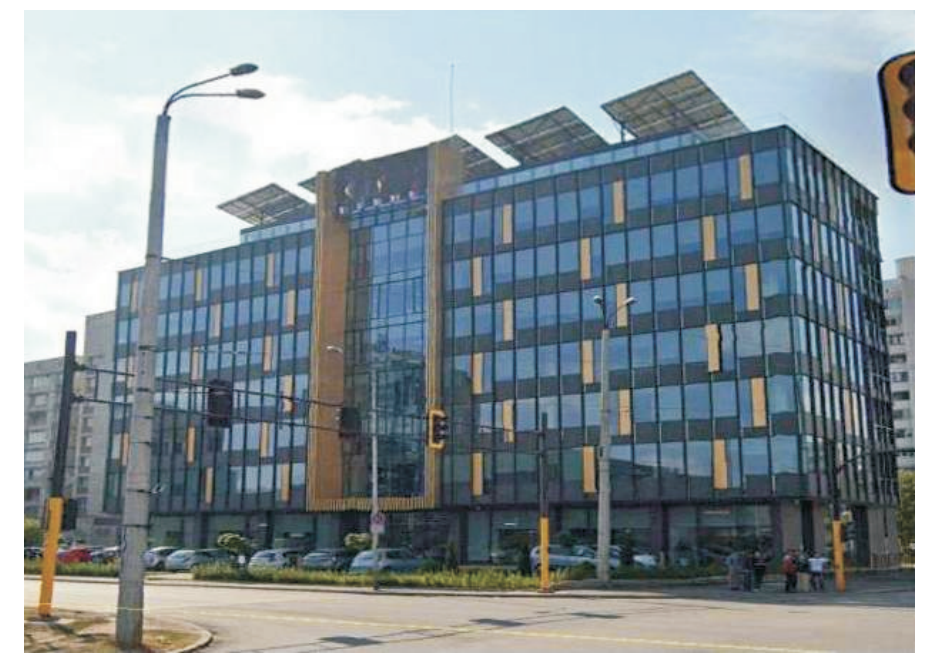

Fig. 4. A building located on Tsarigradsko Road, Sofia an office building meeting the NZEB requirements

At the congress of the European Construction Industry Federation (FIEC) held on May 212021 Madam Kadri Simson, European Commissioner for Energy, noted in her greeting [27] that the EU is at the threshold of an enormous 
change concerning the buildings, i.e. a "rehabilitation wave", which will yield modernization of 35 million buildings in the EU. This is a challenge to the building branch urging it to exit the health crisis and realize a better housing stock. She also noted that "the construction companies are the key to the success of this important initiative, which would result in a drop of electricity consumption yielding achievement of the goals of the Paris climate agreement". We would add here the Green Deal, too. Note also the FIEC position [28] stressing upon the material and technical neutrality to accelerate the "green" and digital transformation. Hence, the planned "Deep rehabilitation" should be popularized and enhanced. It is expected that the building energy renovation will be one of the basic components of the plans for rehabilitation and sustainability of the member states.

The Construction Chamber of Bulgaria founded a "European construction hub" on 27. 05. 2021 [28]. It will be responsible for the introduction of digitalization into the building branch. Thus, small and medium construction companies and the public administration will increase their capacity, knowledge, and skills via digital transformation of the branch. The latter will also face a serious challenge in replacing the current construction equipment after the introduction of pure hydrogen fuel.

\section{CONCLUSION}

The Green Deal implies a drop in the release of greenhouse gases, improvement of the living standard of the European residents, preservation of the environment, judicious use of raw materials, and improvement of the energy characteristics and aesthetics of the buildings. It requires mobility of the government, local authorities, and business mostly, as well as responsible care for innovations, education, clean environment, and ecological transport. The public's role, motivation, behavior, and technical support will enhance in the member states. Communities will also assess the profits of the Green Deal. It will require significant investments. To realize it, the EC will provide 260 billion Euro including $25 \%$ of funds for operative climate programs, $20 \%$ of funds for emission trade, and at least $30 \%$ of the EU Invest fund. Consider also funds for the economy rehabilitation after the COVID-19 pandemic and aid for disadvantaged regions (including 458 million for Bulgaria), as well as investments in regions affected by the requirement for the substitution of energy source materials with pure hydrogen and carbonized natural gas.

The building branch faces a good perspective for development as well as specific responsibilities as participating in the Green Deal realization. Small 
and medium companies, in particular, have the responsible task for active and effective participation in the new "rehabilitation wave". This of course is not reduced to the use of expanded polystyrene for insulation, only, but companies should also adopt measures for deep rehabilitation and provide comfort, better ecological environment, and healthier life of the European residents.

\section{REFERENCES}

[1] Annex to General Assembly Documents, A/42//427.

[2] 2020 Union of Concerned Scientists, Earth Systems Science Data (2019) 11 17831838.

[3] http:/www.data.eu/rapid/press-releas-IP-16-3783-en.htm

[4] K. SchwaB, The Fourth Industrial Revolution (2016), ISBN-13: 978-1-94483501-91.

[5] B. BAROw, http:/www.foreinaffers.com/articles/2015-12-12/forth-Industrial

[6] McKinsey UNFCCC, 2020.

[7] Ya. Ivanov, in: Proceedings of International Conference DCB'2020, pp. 11-22.

[8] http://www.c3isp.eu/content/horizon-europe2021-2027

[9] http://www.euractiv.com//sectiom/ energy-environment/news//brussels

[10] http://euractiv.com/section/energy-environment/opinion/inovation-the-key-tothe-green-deal

[11] http://n.p. Stroitel.bg, 21.04.2021, p.3

[12] www.easac.com/perspective

[13] http://www.FIEC/org.2018, Ya. Ivanov, 2020.

[14] http://www.foreinaffer.com/2018/forth-Industrial

[15] http://www.Business Club-2000-03Pdf

[16] Ya. Ivanov, Sustainable Construction - New Demand for Civil Engineering Practice, in: Proceedings of $11^{\text {th }}$ International Conference Assessment, Maintenance and Rehabilitation of Structure and Settlements, Zlatibor, 2019, pp 43-54.

[17] Ya. Ivanov and V. Angelieva, Sustainable Construction Requirement and Contribution for the Protection of Nature and Sustainable Development, in: X Jubilee International Conference DSB'2018, pp. 29-39.

[18] Ya. Ivanov, Sustainable Construction with Contribution to Sustainable Development, in: Proceedings of VIII International Conference ArCivE'2017, pp. $13-19$.

[19] P. De VRIEs, in: Proceedings of $5^{\text {th }}$ Int. Slag Valorization Symposiun, From Fundamentals to Applications, Leuven, 2017, pp. 313-319.

[20] http://www.euracriv.com/sectiom/energy-environment/news//brussels-rulesout-double-carbon-compensation-for-eu-steelmakers. 
[21] Global $\mathrm{CO}_{2}$ Reduction, Future Chain, Conference and Exhibition, in: Proc. Brussels 22-23 May, 2019.

[22] De Crisforo and N. Etal. in: Proceedings of First International Conference CoMS'2017, Zadar, Croatia, 2017, pp. 65-70.

[23] E. Manolova and Ya. Ivanov, Innovations in Material Science in Response to Sustainable Construction Requirement, Science (2020) XXX (5) 17-23 (in Bulgarian).

[24] Construction Industry Value Chain, Carbon Pricing Leadership, Iinternational Finance Corporation (2021).

[25] G. Nikolova, A. Yanakieva, and Ya. Ivanov, in: Proceedings of the International Conference DCB'2015, pp. 31-43.

[26] G. Nikolova, A. Yanakieva, Ya. Ivanov, and R. Kazandjiev, in: Proceedings of International Conference ESI'2017, pp. 139-149.

[27] http://n.p. Stroitel.bg, 28.05.2021, p.8

[28] http://n.p. Stroitel.bg, 28.05.2021, p.1

Received June 18, 2021

Engineering Sciences, LVIII, 2021, No. 3 